\title{
ENDO180 AND MT1-MMP ARE INVOLVED IN THE PHAGOCYTOSIS OF COLLAGEN SCAFFOLDS BY MACROPHAGES AND IS REGULATED BY INTERFERON-GAMMA
}

\author{
Qingsong Ye 1,2,3, Quan Xing ${ }^{2}$, Yijin Ren ${ }^{2}$, Martin C. Harmsen ${ }^{1}$, and Ruud A. Bank ${ }^{1, *}$ \\ ${ }^{1}$ Stem Cell \& Tissue Engineering Research Group, Medical Biology, University Medical Centre Groningen, \\ University of Groningen, Groningen, The Netherlands \\ ${ }^{2}$ Orthodontics, University Medical Centre Groningen, University of Groningen, Groningen, The Netherlands \\ ${ }^{3}$ Current address: Orthodontics, James Cook University, Townsville, Queensland, Australia
}

\begin{abstract}
Subcutaneously implanted disks of hexamethylenediisocyanate or glutaraldehyde cross-linked sheep collagen (referred to as HDSC and GDSC, respectively) in mice show large differences in degradation rate. Although comparable numbers of macrophages are seen in HDSC and GDSC, phagocytosis of collagen by macrophages occurred only in GDSC. The molecular mechanisms involved in the phagocytosis of collagen by macrophages are essentially unknown. Immunofluorescence and RT-PCR showed that Endo180 was expressed in GDSC only. TissueFaxs showed that Endo180 co-localized with MT1MMP on F4/80 positive cells, which is likely responsible for the phagocytosis in GDSC. RT-PCR further showed that Endo180 expression correlated with high levels of IFN$\gamma$ mRNA. In vitro, IFN- $\gamma$ induced the expression Endo180 and MT1-MMP in murine macrophages cultured on collagen type I (although too high levels of IFN- $\gamma$ dampened the expression of Endo180 and MT1-MMP). Moreover, the expression of Endo180 and MT1-MMP induced by IFN$\gamma$ can be inhibited through IL-10. The differences in microenvironment between GDSC and HDSC (high IFN$\gamma$ and low IL-10 levels in GDSC, low IFN- $\gamma$ and high IL10 levels in HDSC) provide an explanation why phagocytosis of collagen by macrophages is only seen in GDSC. In summary, we show for the first time that the IFN- $\gamma$ dependent co-expression of Endo180 and MT1MMP on macrophages coincides with collagen phagocytosis, thus providing evidence that the mechanism of collagen phagocytosis operating in the foreign body reaction by macrophages is comparable with the mechanism of intracellular collagen degradation by fibroblasts seen under physiological conditions.
\end{abstract}

Keywords: Phagocytosis, foreign body reaction, collagen receptor, Endo180, interferon- $\gamma$.

*Address for correspondence:

R.A. Bank or Qingsong Ye

Stem Cell and Tissue Engineering Research Group,

Dept. of Pathology and Medical Biology,

University Medical Center Groningen, University of Groningen, Hanzeplein 1, EA11

9713 GZ Groningen

The Netherlands

Telephone Number: +31503611983

FAX Number: +31 503619911

E-mail: R.A.Bank@med.umcg.nl or qingsongye@hotmail.com
Introduction

The interaction of tissues with biomaterials is a field of crucial importance to all kinds of medical technologies, including tissue engineering (Sachlos et al., 2006; Tai et al., 2007; Munirah et al., 2008). The tissue response towards implanted biomaterials, also called the foreign body reaction, is influenced to a large degree by the morphology and composition of the biomaterial, and the location where the biomaterial is implanted (Luttikhuizen et al., 2006a; Anderson and Jones, 2007; Yeghiazaryan et al., 2007; Anderson et al., 2008; Dinnes et al., 2008). By changing certain biochemical or biophysical characteristics (Khouw et al., 1998; Van Putten et al., 2009), the tissue response will alter, for example by attracting more or specific cells to the scaffold. The microenvironment of the implant further changes due to the secretion of proteins by the attracted cells as they secrete cytokines and/or chemokines. The microenvironment by itself also has a major impact on the phenotypic properties of macrophages (Luttikhuizen et al., 2006b; Luttikhuizen et al., 2007), a cell type that plays a central role in the outcome of the foreign body reaction (Brown et al., 2009; Valentin et al., 2009). Macrophage activation gives rise to different populations of cells with distinct functions (Mosser and Edwards, 2008), and it has been shown that the phenotype of the macrophages participating in the foreign body reaction is a determinant of biological scaffold remodelling (Badylak et al., 2008; Brown et al., 2009).

Collagen scaffolds are often used in tissue engineering. We have recently observed that there are marked differences in the degradation rate of two differently crosslinked dermal sheep collagen scaffolds (hexamethylenediisocyanate and glutaraldehyde cross-linked, referred to as HDSC and GDSC, respectively) in mice implanted in one anatomical location, namely subcutaneously (Ye et al., submitted). GDSC disks were almost completely degraded after four weeks, whereas HDSC disks did not degrade after four weeks. Phagocytosis was seen in GDSC disks at certain time points (day 2 and day 21); furthermore, increased matrix metalloproteinase (MMP) activities were seen. In HDSC disks, no phagocytic activity was seen, and collagenolytic activity was effectively inhibited by increased levels of the tissue inhibitor of matrix metalloproteinase TIMP-1. Phagocytosis of GDSC coincided with high levels of interferon-gamma (IFN- $\gamma$ ) in the microenvironment; in HDSC disks less IFN- $\gamma$ is seen in combination with increased levels of interleukin-10 (IL-10). The high levels 
of IFN- $\gamma$ were attributed to the infiltration of neutrophils in GDSC, whereas the increased levels of IL-10 was attributed to the presence of giant cells in HDSC (Ye et al., submitted).

Although phagocytosis of the collagen by macrophages has repeatedly been reported (Parakkal, 1969; Knapp et al., 1974; Deporter, 1979; Svoboda and Deporter, 1980; Inouye et al., 1983; Ciapetti et al., 1996; Lucattelli et al., 2003), and it is intuitive and logical that phagocytic cells such as macrophages are involved in phagocytosis of collagen bundles, essentially nothing is known about this phenomenon in the foreign body reaction and the mediators of this process. In fibroblasts, phagocytosis and intracellular digestion of collagen is intensively studied (Everts et al., 1996). The membrane-bound matrix metalloproteinase MT1-MMP plays an essential role in collagen phagocytosis of fibroblasts (Beertsen et al., 2002; Lee et al., 2006; Lee et al., 2007). It has recently been postulated that the urokinase plasminogen activator receptor-associated protein (also known as uPARAP or Endo180) is, in combination with the membrane-bound matrix metalloproteinase MT1-MMP, responsible for the phagocytic uptake of collagen by fibroblasts (Engelholm et al., 2003b; Madsen et al., 2007). Endo180 is a membrane-bound receptor that is able to bind collagen and is involved in the subsequent endocytic collagen uptake (East et al., 2003; Behrent and Bugge (2003); Wienke et al., 2003; Kjoller et al., 2004; Curino et al., 2005; Mousavi et al., 2005; Thomas et al., 2005). Although Endo180 has been reported to be present on macrophages (Sheikh et al., 2000; Honardoust et al., 2006), nothing is known about its role in collagen phagocytosis by macrophages. In this paper we have investigated whether there is a relationship between the expression of Endo180 and MT1-MMP and the presence/absence of collagen phagocytosis by macrophages in GDSC and HDSC, respectively. Furthermore, we investigated whether IFN- $\gamma$ and IL-10 are involved in the regulation of Endo 180 and MT1-MMP expression.

\section{Materials and Methods}

\section{Biomaterial processing}

Non-crosslinked dermal sheep collagen (DSC), processed from sheep skin, was obtained from the Zuid-Nederlandse Zeemlederfabriek (Oosterhout, the Netherlands). DSC was crosslinked with either glutaraldehyde (henceforth referred to as GDSC) or hexamethylenediisocyanate (henceforth referred to as HDSC), according to the protocols described previously (Van Wachem et al., 1994; Olde Damink et al., 1995). Disks (6 $\mathrm{mm}$ in diameter, $0.75 \mathrm{~mm}$ in thickness) were punched from pieces of HDSC and GDSC from the same batch, and sterilized with ethylene oxide. Endotoxin content of surface-associated endotoxin levels of Col-I disks were below $0.25 \mathrm{EU} / \mathrm{ml}$, as determined by the LALmethod (LAL kinetic-QCL ${ }^{\circledR}$; Cambrex, East Rutherford, NJ, USA).

\section{Animals and operating procedures}

All procedures performed on animals were approved by the local committee for care and use of laboratory animals of the University of Groningen and were performed according to international and governmental guidelines on animal experimentation. Male C57BL/6 mice (10 weeks old, Harlan, Horst, The Netherlands) were housed individually in a conventional condition with food and water ad libitum. Mice were anaesthetized with $4 \%$ isoflurane and maintained by $2 \%$ isoflurane inhalation in combination with a mixture of equal volumes of $\mathrm{N}_{2} \mathrm{O}$ and $\mathrm{O}_{2}$. The back was shaved and disinfected with chlorhexidine, two incisions were made and subcutaneous pockets were created on both sides. The HDSC or GDSC scaffolds were implanted about one centimetre away from the incision site, thus minimising the effect of wound healing on the foreign body reaction itself. The incisions were closed with 6-0 non-absorbable Prolene sutures. Finally, mice received pure oxygen until awakening. The Col-I disks (HDSC or GDSC) were removed at the following time points after implantation (related to the different phases of the FBR in mice): 2 days (onset), 7 days (early progression), 14 and 21 days (intermediate progression), and 28 days (late progression), $n=6$ per time point. The disks were snap-frozen in liquid nitrogen immediately after explantation.

\section{Cell culture and interventions}

The murine monocytic macrophage cell line RAW 264.7 (American Type Culture Collection, ATCC, Manassas, VA, USA) was cultured in RPMI-1640 (BioWhittaker, Verviers, Belgium) with $10 \%$ foetal bovine serum (FBS), supplemented with $2 \mathrm{mM}$ glutamine, $100 \mu \mathrm{g} / \mathrm{ml}$ streptomycin and $100 \mathrm{IU} / \mathrm{ml}$ penicillin.

The 6-well cell culture plates (BD Falcon ${ }^{\mathrm{TM}}$, Franklin Lakes, NJ, USA) and 6-well diagnostic slides (MenzelGlaser, Braunschweig, Germany) were coated overnight at $37^{\circ} \mathrm{C}$ in a humidified $5 \% \mathrm{CO}_{2}$ atmosphere using 300 $\mu \mathrm{g} / \mathrm{ml}$ rat tail type I collagen (BD Bioscience) in $1 \mathrm{mM}$ $\mathrm{NaOH} / \mathrm{PBS}(1 \mathrm{ml} /$ well for culture plates and $100 \mu \mathrm{l} /$ well for diagnostic slides). RAW 264.7 cells $\left(1.2 \times 10^{4}\right.$ cells/ $\mathrm{cm}^{2}$ ) were seeded into 6-well cell culture plates and 6well diagnostic slides with or without collagen coating. After a preincubation of 24 hours, the cells were treated with different concentrations of inflammatory mediators: recombinant human IFN- $\gamma$ (PeproTech, London, UK) from 0 to $25 \mathrm{ng} / \mathrm{ml}$, recombinant human IL-1 $\beta$ (PeproTech) from 0 to $25 \mathrm{ng} / \mathrm{ml}$, recombinant murine TNF- $\alpha$ (BioVision, Mountain View, CA, USA) from 0 to $25 \mathrm{ng} / \mathrm{ml}$, and recombinant murine IL-10 (R\&D Systems Inc., Minneapolis, MN, USA) from 0 to $25 \mathrm{ng} / \mathrm{ml}$ together with $2.5 \mathrm{ng} / \mathrm{ml}$ human IFN- $\gamma$. All cells were subsequently incubated at $37^{\circ} \mathrm{C}$ in a humidified $5 \% \mathrm{CO}_{2}$ atmosphere for $48 \mathrm{~h}$. The cells in the culture plates were then harvested for gene expression analysis by Reverse Transcription Polymerase Chain Reaction (RT-PCR), and cells on the slides were used for in situ detection of Endo 180 and MT1-MMP proteins by immunofluorescence staining. $\mathrm{N}=5$ for all in vitro experiments. 


\section{Gene expression analysis}

One $\mu \mathrm{g}$ of total RNA (either extracted from snap frozen explants or RAW 267.4 cells) was used to generate the first strand cDNA synthesis using M-MuLV reverse transcriptase (MBI Fermentas, St. Leon-Rot, Germany) and random hexamer primers, according to the manufacturer's protocol. Ten ng of cDNA were used for each PCR reaction. PCR for Endo180, IFN- $\gamma$ and the housekeeping gene $\beta$ actin was performed in a final reaction volume of $25 \mu \mathrm{l}$ containing $1.5 \mathrm{mM} \mathrm{MgCl}, 0.25 \mathrm{mM}$ dNTP mix, $1 \mu \mathrm{M}$ primer Mix and $1 \mathrm{U}$ Taq DNA polymerase.

\section{Primer sequences \\ Endo180 \\ GGCATCACTGTAGATCACTTGG (forward) \\ ATCCGAGCACAGCGCTAGGG (reverse) \\ IFN- $\boldsymbol{\gamma}$ \\ TGGAGGAACTGGCAAAAGGATGGT (forward) \\ TTGGGACAATCTCTTCCCCAC (reverse) \\ $\beta$-actin \\ GTGAAAAGATGACCCAGATCAT (forward) \\ GCTTCTCTTTGATGTCACGCACGAT (reverse)}

Amplification was performed on a MyCycler (Bio-Rad, Hercules, CA, USA) for 35 cycles at annealing temperature of $66^{\circ} \mathrm{C}, 56^{\circ} \mathrm{C}$ and $60^{\circ} \mathrm{C}$ for Endo 180 , IFN- $\gamma$ and $\beta$-actin, respectively. The amplimers were separated in a $2 \%$ agarose gel.

\section{Immunofluorescence microscopy}

Expression of Endo180 and MT1-MMP in vivo and in vitro was verified by means of in situ immunofluorescent staining on explants of two materials at all time points and on cells cultured on the diagnostic slides. Tissue sections $(5 \mu \mathrm{m})$ were mounted on silane-coated slides. Both cryosections and cell cultured slides were fixed with $2 \%$ paraformaldehyde (PFA)/PBS at room temperature (RT) for $10 \mathrm{~min}$, then washed in $0.1 \%$ Triton X-100 in PBS (5 min) for 3 times. After that, samples were incubated with 1:100 goat anti-mouse Endo180 antibody (Santa Cruz Biotechnology, Santa Cruz, CA, USA ) and 1:200 rabbit anti-mouse MT1-MMP antibody (Epitomics Inc., Burlingame, CA, USA) in PBS with $0.5 \%$ Triton X-100 and $2 \%$ normal goat serum for $2.5 \mathrm{~h}$ in the dark at RT. After incubation, samples were washed in $0.1 \%$ Triton X100 in PBS ( $5 \mathrm{~min}$ ) for 3 times. The secondary antibody for MT1-MMP, namely swine anti-rabbit FITC $(1: 100$, Dako, Carpinteria, CA, USA) in PBS with 4',6-diamidino2-phenylindole (DAPI, 1:5000, Sigma-Aldrich, Zwijndrecht, The Netherlands), was incubated for $30 \mathrm{~min}$. Samples were then washed in $0.1 \%$ Triton X-100 in PBS ( $5 \mathrm{~min}$ ) for 4 times to wash off non-bound secondary antibodies (FITC). The secondary antibody for Endo180, namely rabbit anti-goat Cy3 (1:100, Zymed Laboratories Inc., San Francisco, CA, USA) in PBS with DAPI (1:5000) was incubated for $30 \mathrm{~min}$. Next, samples were washed 4 times in $0.1 \%$ Triton X-100 in 1x PBS ( $5 \mathrm{~min}$ ) to wash off the secondary antibodies (Cy3). Samples were mounted with Citifluor (London, UK) followed by examination under the immunofluorescence microscope.
To unravel the identity of the Endo180 expressing cells, a double staining was performed as described above using the previously mentioned Endo180 antibodies (in combination with rabbit anti-goat $\mathrm{Cy} 3$ ) together with a murine macrophage marker, rat anti-mouse F4/80 antibodies (1:100, Serotec Ltd. Oxford, UK). After incubation in combination with .with primary antibodies for $2.5 \mathrm{~h}$, The secondary antibody for Endo180 (1:100, rabbit anti-goat Cy3) in PBS with DAPI (1:5000) was added and incubated for $30 \mathrm{~min}$. Samples were then washed in $0.1 \%$ Triton X-100 in PBS (5 min) for 4 times to wash off non-bound secondary antibodies (Cy 3 ). The secondary antibody for F4/80, namely goat anti rat FITC (1:100; Southern Biotech, Birmingham, AL, USA) was incubated for $30 \mathrm{~min}$. thereafter, samples were washed 4 times in $0.1 \%$ Triton X-100 in 1x PBS (5 min) to wash off the secondary antibodies (FITC). Finally, samples were mounted with Citifluor followed by examination under the immunofluorescence microscope.

For the negative controls, samples were stained as described above, except that the primary antibodies were replaced with the same dilution of serum from the same species as used for the specific first antibodies, namely, normal goat serum $(1: 100$, Sanquin Pharmaceutical Services, Amsterdam, Netherlands), normal rabbit serum (1:200, Dako, Carpinteria, USA) and normal rat serum (1:100, Invitrogen, Carlsbad, CA, USA) for Endo180, MT1-MMP and F4/80, respectively.

Each section was viewed using a Leica DMRXA Immumofluorescence microscope (Leica Microsystems, Rijswijk, The Netherlands) with FITC and Cy3 filter, fitted with a Leica DC350 FX high resolution fluorescence digital camera and Leica Qwin Pro image analysis software. A compensation procedure was performed to prevent the influence of the overlap between FITC and Cy3.

\section{Quantification of Endo180 and MT1-MMP immunostaining}

To further quantify the number of cells with Endo180, MT1-MMP and F4/80 immunostaining, three representative images (magnification: $40 \times$ ) of each tissue section were analyzed with TissueFaxs ${ }^{\circledR}$, Zeiss AxioImager Z1 Microscope System (Tissue-Gnostics GmbH, Vienna, Austria). Single cells were identified by their nuclei (DAPI staining). This identification mask was then applied to determine gray values in the two corresponding channels FITC (MT1-MMP or F4/80) and Cy3 (Endo180) of each object in all images. The percentage of MT1-MMP or F4/ 80 and Endo180 positive cells was determined and depicted as scattergrams. Each scattergram represents average values calculated from analysis of all three images of one entire tissue section. Based on the degree of fluorescence intensity in the negative controls, appropriate threshold values for positive immunofluorescence staining were defined. Pictures were digitised, analysed, and protein expression was quantified. To quantify the fraction of MT1-MMP and Endo180 positive cells cultured on 6-well diagnostic slides, four representative fields $(20 \times)$ were taken in each well. Percentages of MT1-MMP or Endo180 
A.

GDSC

HDSC
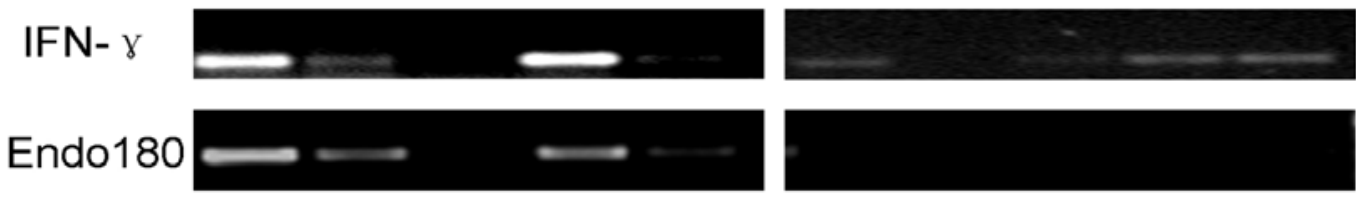

ß-actin
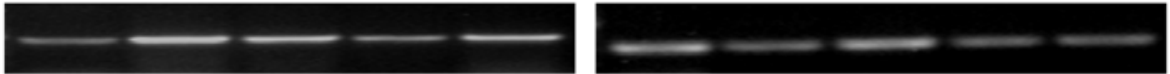

day

$\begin{array}{lllll}2 & 7 & 14 & 21 & 28\end{array}$

$\begin{array}{lllll}2 & 7 & 14 & 21 & 28\end{array}$
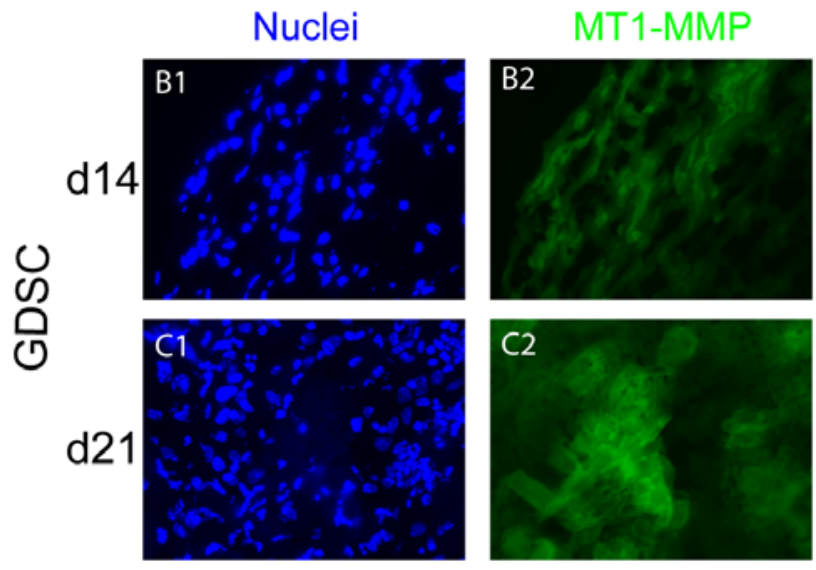

Endo 180
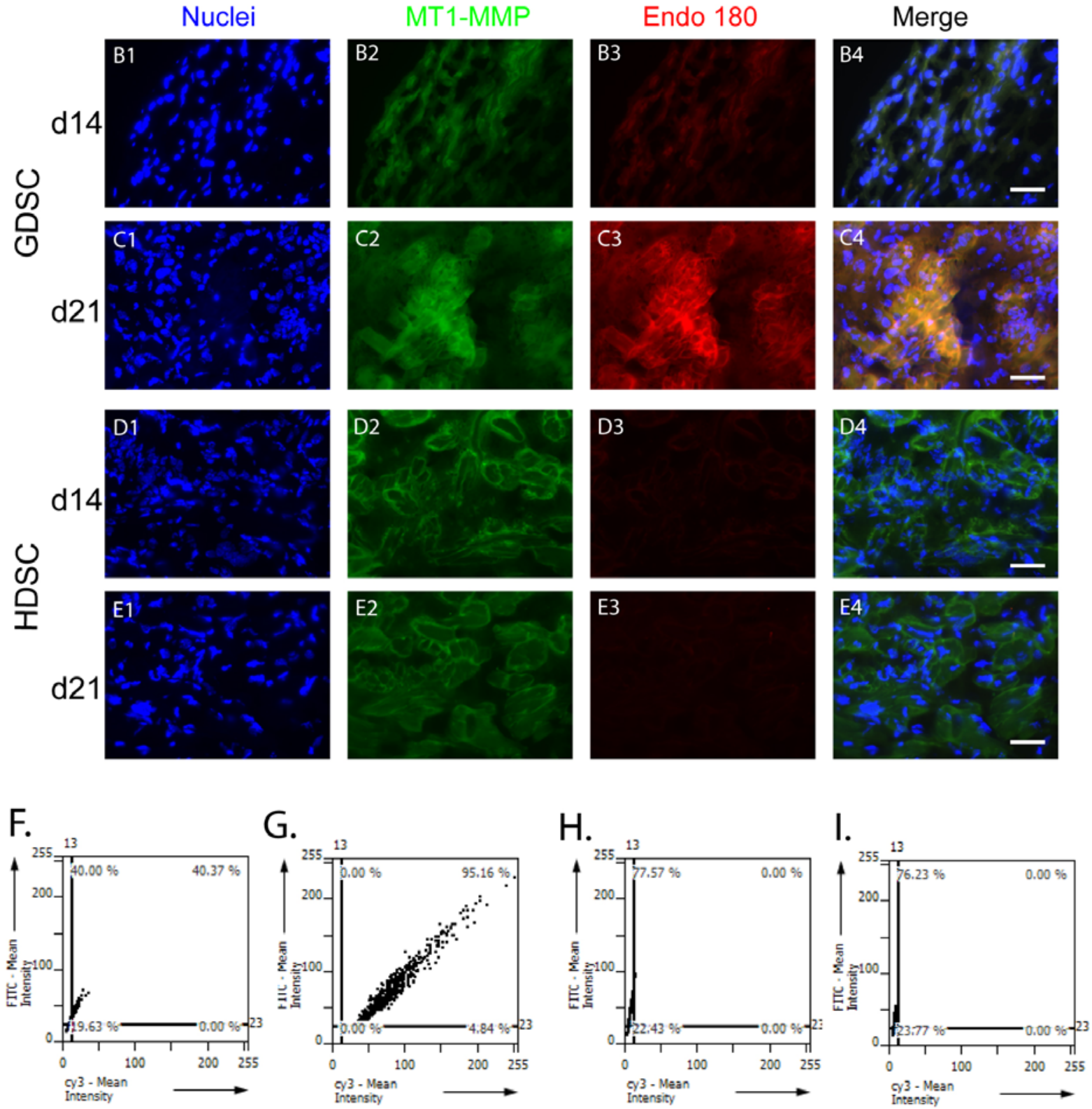

Fig. 1. Gene transcript and/or protein expression analysis of IFN- $\gamma$, MT1-MMP and Endo180 in HDSC and GDSC scaffolds during the foreign body reaction in mice. Gene transcript was performed for IFN- $\gamma$ and Endo 180 in both collagen scaffolds at all time points (A). Protein expression analysis of MT1-MMP and Endo180 in HDSC and GDSC scaffolds at day 14 (B1-B4, D1-D4) and day 21(C1-C4, E1-E4): MT1-MMP protein (FITC, green) was expressed in both biomaterials (B2, C2, D2, E2). In contrast, the expression of Endo180 (Cy3, red) was mainly observed in GDSC at day 21 (C3) and low at day 14 (B3). In HDSC, Endo180 expression was not observed (D3, E3). Cell nuclei were stained with DAPI (blue). Scale bar $=20 \mu \mathrm{m}$. Quantification of MT1-MMP and Endo180 expression in GDSC and HDSC using TissueFaxs ${ }^{\circledR} 2.2$ (F-I): Scattergrams $(n=3)$ show the percentages of cells that co-expressed MT1-MMP and Endo180 proteins in GDSC (F,G) and HDSC (H,I) at day 14 and day 21, respectively. 
positive cells were determined through counting the total cell number and the number of MT1-MMP or Endo180 positive cells in each micrograph. The experiments were repeated 4 times. Data from these experiments $(n=5)$ were presented as average percentage of positive cells.

\section{Statistical analyses}

All quantitative data are indicated as mean \pm standard deviation (SD). The data were analyzed using statistical software (GraphPad Prism, GraphPad Software, La Jolla, CA, USA). Differences were analyzed by two-way ANOVA followed by post hoc Tukey's test. A difference of $p<0.05$ was considered statistically significant.

\section{Results}

\section{Phagocytosis of collagen bundles is correlated with the co-expression of the membrane proteins MT1- MMP and Endo180}

We have shown previously that phagocytosis of implanted collagen by macrophages was observed in GDSC at day 2 and day 21 (and not at day 7, 14 and 28). Mononuclear cells closely aligned to the biomaterial were considered phagocytic macrophages, especially when the cells show an accumulation of vacuoles or when the biomaterial has a more irregular shape opposite the cell (Fig. 2E). In HDSC, phagocytosis was never observed. Since nothing is known about the molecular mechanisms how macrophages phagocytose collagen, here we continue our previous study regarding GDSC and HDSC disks to further investigate the expression of Endo180 and MT1-MMP, membranebound proteins that are known to be involved in the phagocytosis of collagen in fibroblasts. In GDSC the Endo180 gene was expressed at days 2, 7 and day 21, but its expression was absent in HDSC at all time points (Fig. 1A). In GDSC, immunohistochemistry revealed that although MT1-MMP was expressed throughout the whole course of the FBR (Fig. 1, B2 and C2), but the expression of Endo 180 was mainly observed at day 2 (data not shown) and day 21 (Fig. 1, C3). As phagocytosis of collagen by macrophages was observed only at day 2 and day 21, it seems likely that co-expression of Endo180 with MT1MMP is needed to phagocytose collagen. Double immunofluorescence staining revealed that Endo180 and MT1-MMP co-localized on the cells (Fig. 1, B4 and C4); this was further substantiated by TissueFaxs (Fig. 1, F and G). In HDSC, MT1-MMP was expressed at all time points (Fig. 1, D3 and E3), yet Endo180 protein was never expressed throughout the whole course of the foreign body reaction (Fig. 1, D3, E3, H and I). As in HDSC no phagocytosis of collagen is seen, the HDSC data provide additional evidence that expression of Endo180 seems to be a prerequisite for the phagocytosis of collagen by macrophages.

Double immunofluorescence staining of GDSC at day 21 (Fig. 2, A1-D1) revealed that Endo180 was exclusively expressed on macrophages, as all Endo180 positive cells are positive for F4/80, a monoclonal antibody that specifically recognizes mouse macrophages (Austyn and Gordon, 1981). This shows that the phagocytic activity seen in GDSC should be attributed to the macrophages, and not to e.g. fibroblasts. Interestingly, over $90 \%$ of the detected macrophages present in the scaffold showed a co-staining with Endo180 (Fig. 2, A2 to D2). At day 2, also high numbers of Endo $180^{+} \mathrm{F} 4 / 80^{+}$cells are seen, but at this time point also many macrophages are seen that do not show Endo180 expression (data not shown), indicating the presence of various macrophage populations.

\section{IFN- $\gamma$ induces the expression of Endo180 but not MT1-MMP in RAW 264.7 cells cultured without collagen coating}

The microenvironment of GDSC and HDSC disks is governed by the cytokines that are present. At present, the regulation of Endo180 by cytokines has not been investigated. In GDSC disks a high expression of IFN- $\gamma$ was seen at day 2 and 21 with lower levels at other time points, while in HDSC disks low levels of IFN- $\gamma$ is seen during the FBR (Fig. 1A). As the high expression of IFN$\gamma$ at day 2 and 21 coincides with the expression as observed for Endo180 (Fig. 1A and C3), we surmised that IFN- $\gamma$ induces the expression of Endo180. This was tested in vitro with the murine macrophage cell line RAW 264.7. Endo180 expression was tested in RAW 264.7 cells stimulated for 48 hours with a concentration series of IFN$\gamma$. Expression of Endo180 was induced with $1 \mathrm{ng} / \mathrm{ml} \mathrm{IFN-}$ $\gamma$, showed maximum levels at 2.5 and $5 \mathrm{ng} / \mathrm{ml}$ and, decreased at $10 \mathrm{ng} / \mathrm{ml}$, and was near absent at $25 \mathrm{ng} / \mathrm{ml}$ (Fig. 2, B2-E2 and F). IFN- $\gamma$ stimulation did not induce the expression of MT1-MMP in the absence of collagen coating (Fig. 3, B1-E1 and F). The expression of Endo180 after IFN- $\gamma$ stimulation in macrophages was confirmed by RT-PCR (Fig. 3A).

\section{IFN- $\gamma$ induces the expression of Endo180 and MT1- MMP in RAW 264.7 cells cultured on collagen type I}

The responses of cells depend on the extracellular matrix proteins that are contacted. Therefore, we repeated the experiments with RAW 264.7 cells cultured on collagen, because collagen is the substrate that macrophages encounter when they invade the collagen disks in vivo. Expression of Endo180 was high with 1 and $2.5 \mathrm{ng} / \mathrm{ml}$, but the expression of Endo180 decreased at higher levels of IFN- $\gamma(5,10$ and $25 \mathrm{ng} / \mathrm{ml})$ (Fig. 4, B2-E2 and F). Thus as with the non-coated substrate, Endo180 is firstly upregulated and then down-regulated, although the sensitivity differed. However, a remarkable difference was seen with regard to the expression of MT1-MMP: on collagen, the expression pattern of MT1-MMP was comparable to the expression of Endo180 (Fig. 4, B1-E1 and F). Double immunofluorescence staining showed that the Endo180expressing cells co-expressed MT1-MMP (Fig. 4, C3-E3). The expression of Endo180 under IFN- $\gamma$ stimulation in macrophages with collagen coating was confirmed by RTPCR (Fig. 4A).

\section{Expression of Endo180 and MT1-MMP in RAW 264.7 cells was not induced by TNF- $\alpha$ or IL-1 $\beta$}

To determine whether the expression of Endo180 and/or MT1-MMP can be induced by other pro-inflammatory cytokines, RAW 264.7 cells were cultured with collagen 

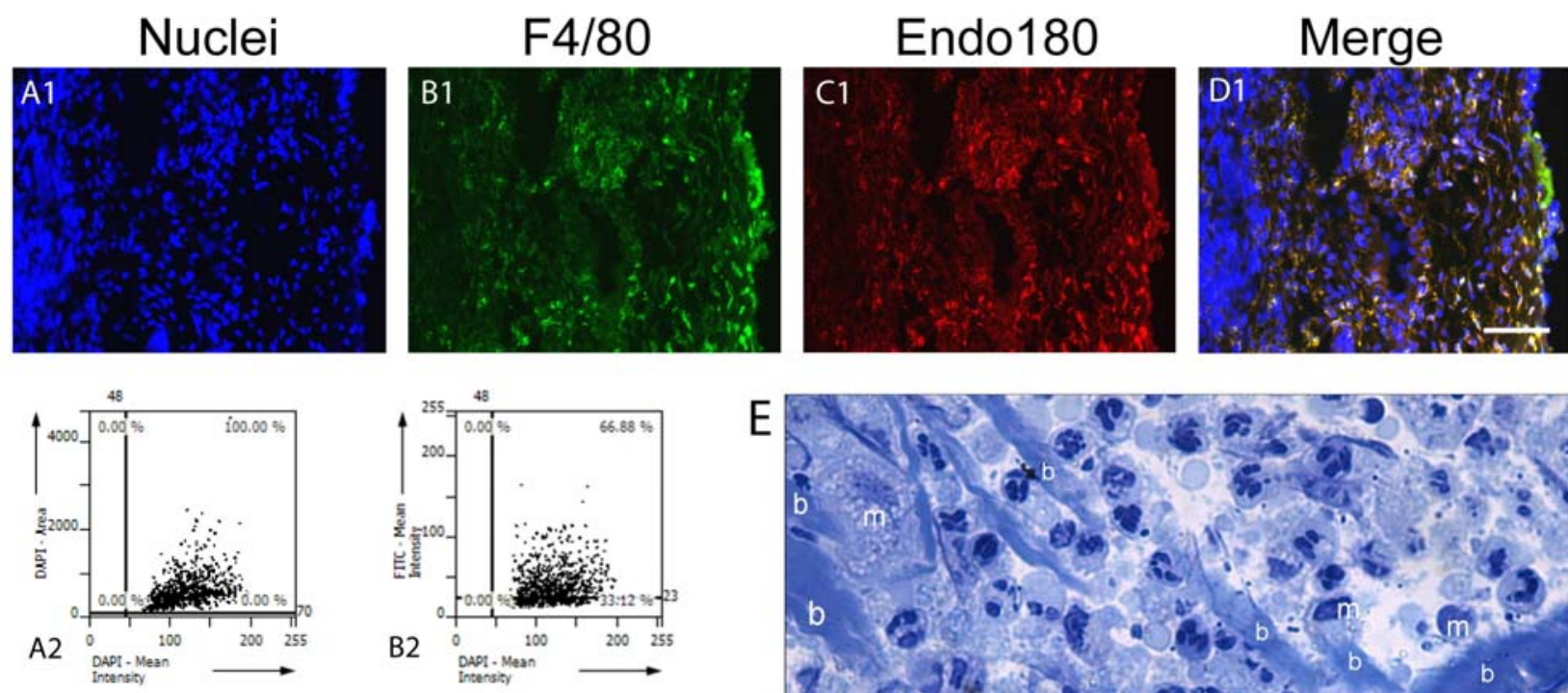

E
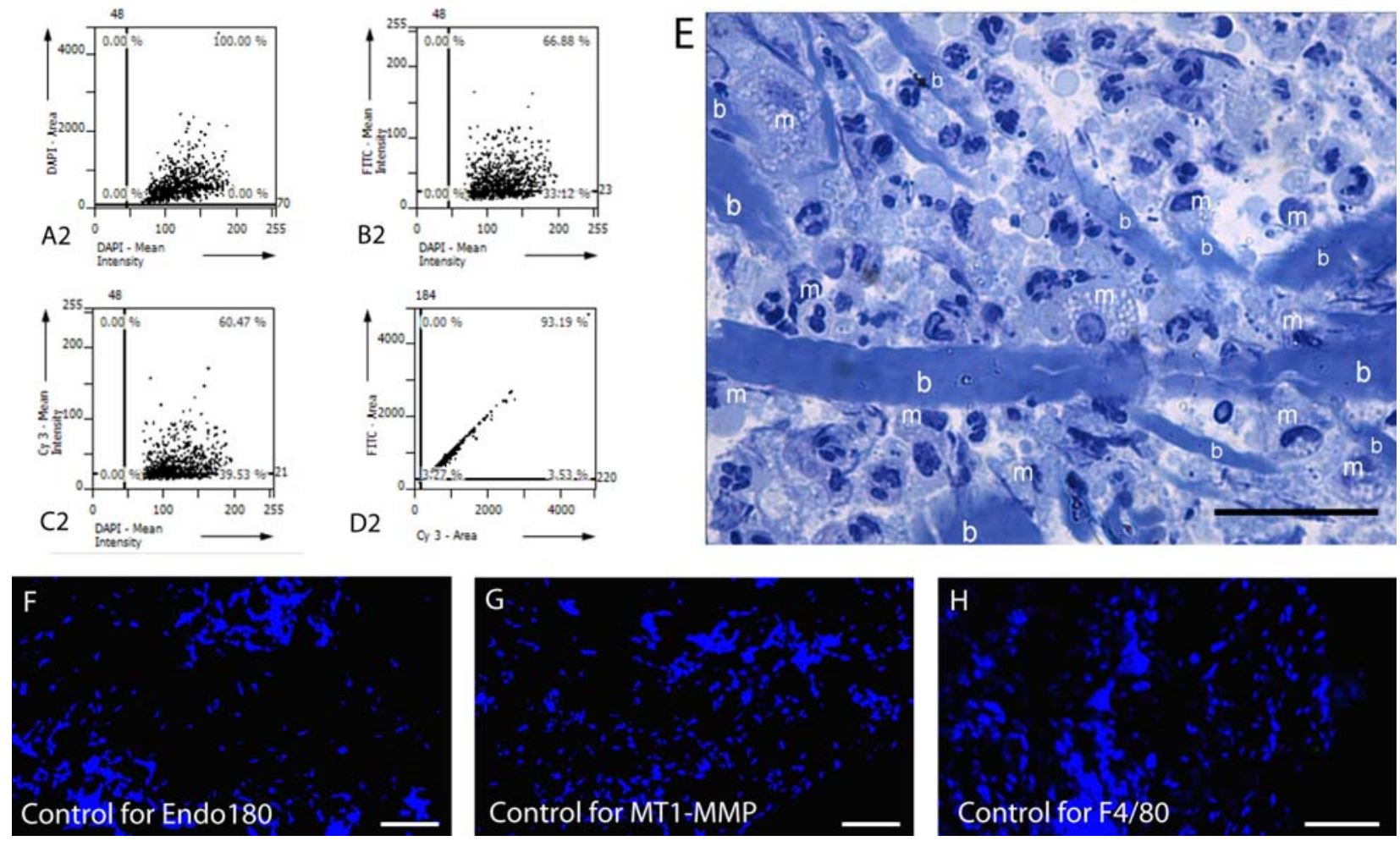

Fig. 2. Endo180 (Cy3, red) is expressed (day 21) on cells that are positive for the macrophage marker F4/80 (FITC, green) (A1-D1). Quantification of Endo180 and F4/80 expression on day 21 using TissueFaxs ${ }^{\circledR}$ (A2-D2): the scattergrams show that the percentage of F4/80 positive cells that co-expressed Endo180 is $>90 \%$. Scale bar $=50$ $\mu \mathrm{m}$. In figure E macrophages are shown (marked with $\mathrm{m}$ ) that phagocytose the biomaterial (marked with $\mathrm{b}$ ). Scale bar $=15 \mu \mathrm{m}$. Representative micrographs of the negative controls for immunostaining of Endo180 (1:100 normal goat serum + rabbit anti-goat Cy3), MT1-MMP (1:200 normal rabbit serum + swine anti-rabbit FITC) and F4/ 80 $(1: 100$ normal rat serum + goat anti-rat FITC) are shown in figures F, G, H, respectively. Scale bar $=50 \mu \mathrm{m}$.

coating and stimulated with different concentrations of either TNF- $\alpha$ or IL- $1 \beta$ for 48 hours. Our data showed that neither the expression of Endo180 nor MT1-MMP could be induced (Fig. 5). The absence of Endo180 expression under TNF- $\alpha$ or IL- $1 \beta$ stimulation in macrophages was confirmed by RT-PCR (data not shown).

\section{The expression of Endo180 and/or MT1-MMP induced by IFN- $\gamma$ is blocked by IL-10}

To determine whether the expression of Endo180 induced by IFN- $\gamma$ can be affected by the anti-inflammatory cytokine IL-10, we stimulated RAW 264.7 cells with a concentration series of IL-10, in the presence of $2.5 \mathrm{ng} / \mathrm{ml}$ IFN- $\gamma$. Our data showed that, regardless with collagen coating or not, the expression of IFN- $\gamma$ induced Endo180 was 50\% blocked by the exposure of the cells to $1 \mathrm{ng} / \mathrm{ml} \mathrm{IL-10,} \mathrm{and}$ was totally blocked at concentrations of $25 \mathrm{ng} / \mathrm{ml}$ IL-10 and above (Fig. 6, B-I, J and K). The expression of MT1-
MMP was also blocked by IL-10 in accordance with Endo180 in RAW 264.7 cultured on collagen type I (Fig. 6 , F-I and K). The inhibition of IFN- $\gamma$ induced Endo180 expression by IL-10 was further confirmed at mRNA levels by RT-PCR (Fig. 6A).

\section{Discussion}

In the current study, we investigate the molecular mechanisms of collagen phagocytosis by macrophages in the foreign body reaction. We show for the first time that the interplay between Endo180 and MT1-MMP correlated with collagen phagocytosis by macrophages, thus providing evidence that the mechanism of collagen phagocytosis operating in the FBR by macrophages is comparable with the mechanism of intracellular collagen degradation by fibroblasts seen under physiological 
A.
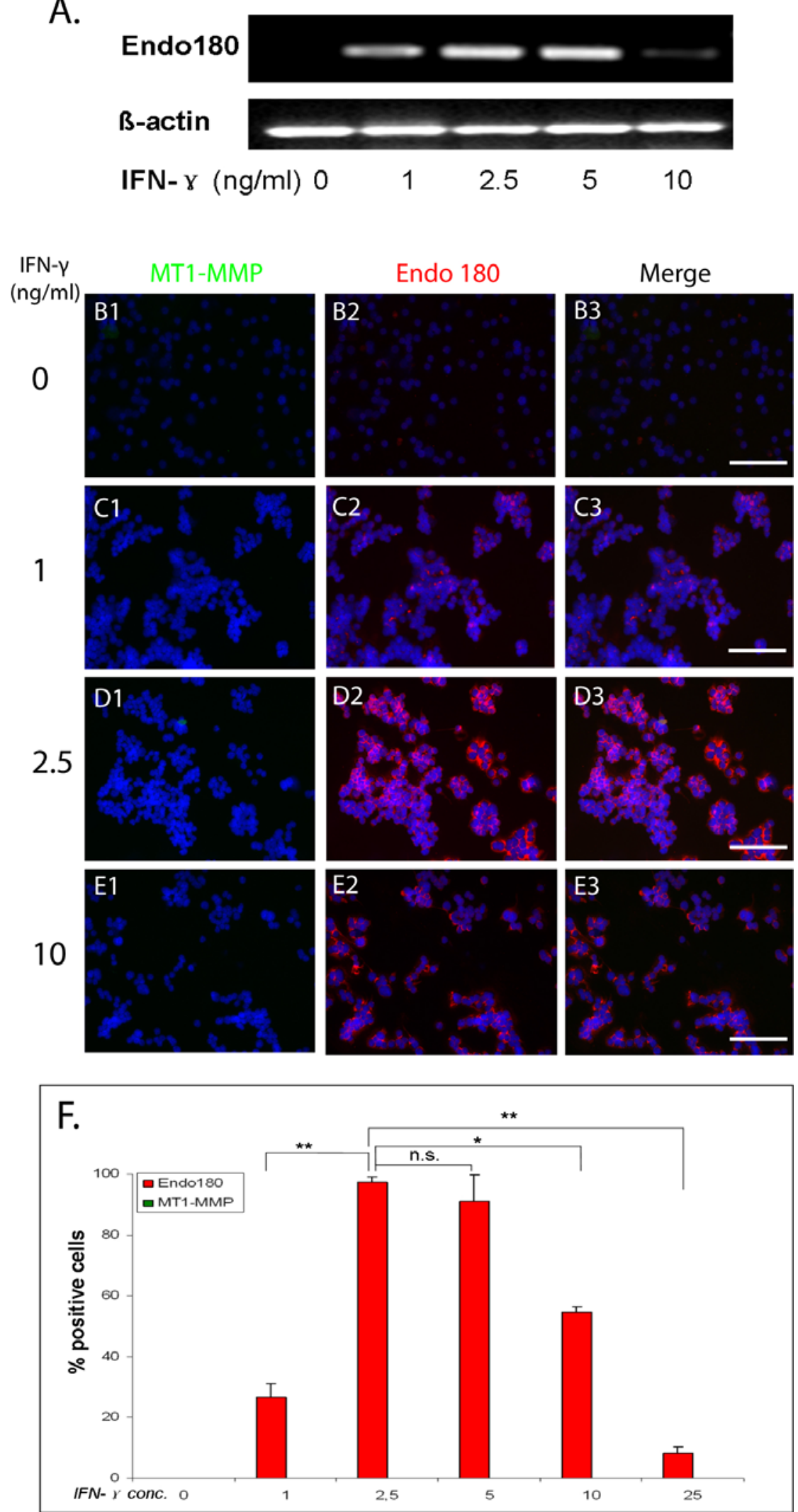

Fig. 3. IFN- $\gamma$ induces the expression of Endo180 but not MT1-MMP in RAW 264.7 macrophages cultured without collagen coating as determined by gene transcript and protein expression analyses. Cells were treated with 0-1-2.55-10-25 ng/ml of IFN- $\gamma$ for $48 \mathrm{~h}$. After that, cells on 6-well cell culture plates and 6-well diagnostic slides were used for RT-PCR and immunofluorescent staining, respectively. mRNA levels of Endo180 was induced with $1 \mathrm{ng} / \mathrm{ml}$ IFN- $\gamma$, showed maximum levels at 2.5 and $5 \mathrm{ng} / \mathrm{ml}$, and decreased dramatically at $10 \mathrm{ng} / \mathrm{ml}$ (A). In consistent with the gene expression, protein expression of Endo180 (red) also exhibited a bell-shape response to the different concentrations of IFN- $\gamma$ (B2-E2 and F). Protein expression of MT1-MMP (green) was not observed (B1-E1 and F). Cell nuclei were stained with DAPI (blue). Values are depicted as mean \pm S.D. $(n=5)$. n.s. $=P>0.05$ (no significant difference); ${ }^{*}=P<0.05 ; * *=P<0.01$. Scale bar $=50 \mu \mathrm{m}$. 
A.
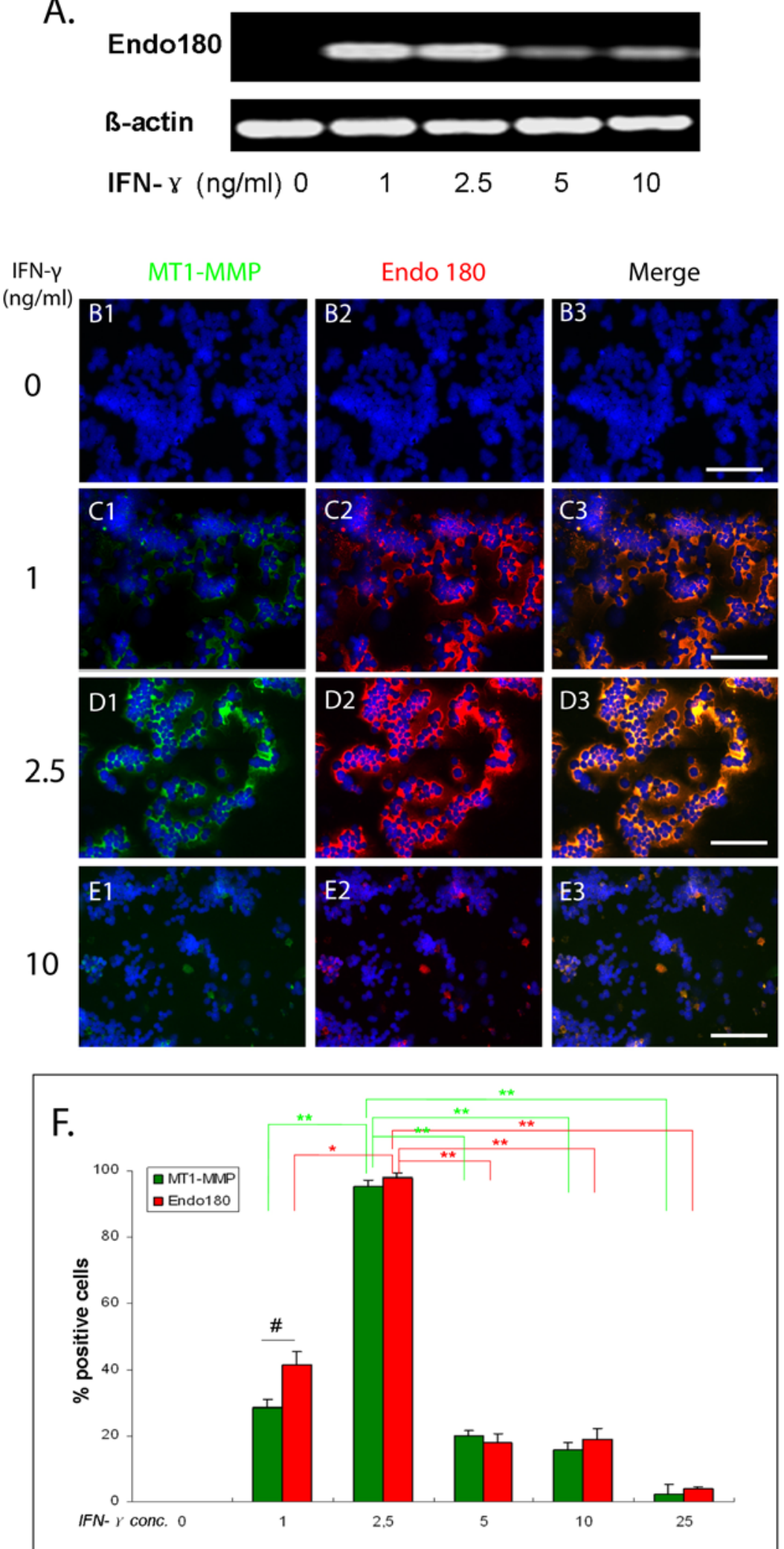

Fig. 4. IFN- $\gamma$ induces the expression of Endo180 and MT1-MMP in RAW 264.7 cultured with collagen coating as determined by gene transcript and protein expression analyses. Cells were treated with 0-1-2.5-5-10-25 ng/ml of IFN- $\gamma$ for $48 \mathrm{~h}$, with the presence of collagen. Thereafter, cells on 6-well cell culture plates and 6-well diagnostic slides were used for RT-PCR and immunofluorescent staining, respectively. mRNA levels of Endo180 was induced with $1 \mathrm{ng} / \mathrm{ml} \mathrm{IFN-} \gamma$, showed maximum levels at 2.5, and decreased dramatically at $5 \mathrm{ng} / \mathrm{ml}$ or above (A). In consistent with the gene expression, the protein expression of Endo180 (red) also exhibited a bell-shape response to the different concentrations of IFN- $\gamma$ (B2-E2 and F). Interestingly, the expression pattern of MT1-MMP (green) was comparable to the expression of Endo180 (B1-E1 and F). The Endo180 and MT1-MMP were co-localized $(\mathrm{C} 3, \mathrm{D} 3)$. Cell nuclei were stained with DAPI (blue). Values are depicted as mean \pm S.D. $(\mathrm{n}=5)$. $*=P<0.05$; $* *$ $=P<0.01$ (comparison within group); \# $=P<0.05$ (Endo180 versus MT1-MMP). Scale bar $=50 \mu \mathrm{m}$. 
Mediators

(ng/ml)

0
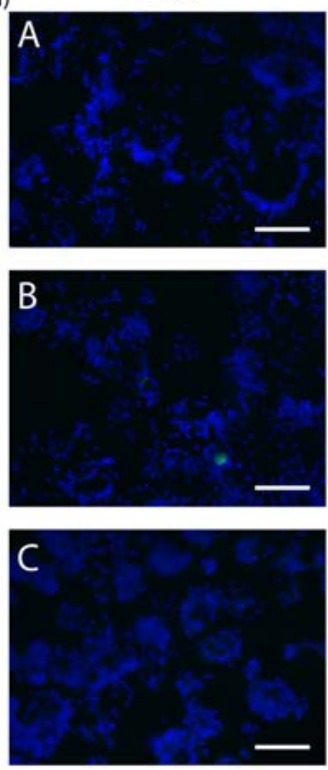

10

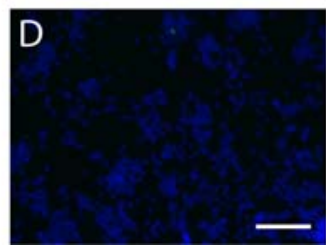

$\mathrm{IL}-1 \beta$
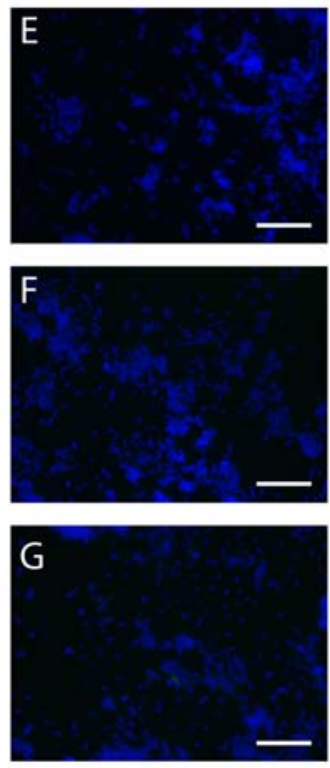

$\mathrm{H}$

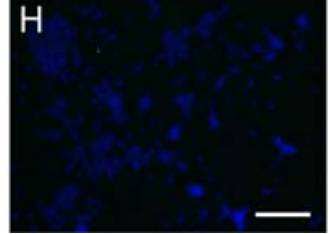

Fig. 5. TNF- $\alpha$ and IL-1 $\beta$ do not induce the expression of Endo180 and MT1-MMP in RAW 264.7 cultured with collagen coating as determined by protein expression analyses with immunofluorescent staining. Neither Endo180 (red) or MT1-MMP (green) was detected on protein level, as shown in the merged picture of double staining of Endo180 and MT1-MMP (A-H). Cell nuclei were stained with DAPI (blue). Scale bar $=50 \mu \mathrm{m}$ conditions. Furthermore, our data showed that the expression of Endo180 and MT1-MMP is regulated by IFN- $\gamma$ with the presence of collagen scaffolds.

We have previously shown that subcutaneously implanted glutaraldehyde or hexamethylenediisocyanate cross-linked dermal sheep collagen disks (GDSC and HDSC) in mice show a high and low degradation rate, respectively (Ye et al., submitted). GDSC provoked the attraction of PMNs at day 2 and 21 after implantation. At both time points, increased levels of IFN- $\gamma$ were seen, as well as phagocytic activity against the GDSC disks (Ye et al., submitted). Although phagocytosis of collagen by macrophages has been repeatedly mentioned, no such reports are available for the foreign body reaction, and surprisingly little is known about the molecular mechanism that is involved in this phagocytosis. A main finding of our current study is that the endocytic transmembrane glycoprotein Endo180, a receptor that is able to bind to collagen and that is essential for cellular uptake of collagen, is highly expressed at day 2 and 21 in GDSC. In addition, we here show that MT1-MMP, a membrane-bound matrix metalloproteinase that is able to cleave collagen fibrils, is also highly expressed at day 2 and 21. Furthermore, we also show that the Endo180 receptor is localized on cells that stain positive for $\mathrm{F} 4 / 80$, i.e. the cells in question are macrophages.

Fibroblasts that lack Endo180 fail to internalize collagen; the same is observed with fibroblasts that have normal Endo180 levels but lack MT1-MMP (Engelholm et al., 2003a; Madsen et al., 2007). This shows that the intracellular uptake of collagen by Endo180 depends on the liberation of collagen from the ECM by limited extracellular proteolysis, i.e. the cleavage of collagen fibrils located near the cell membrane by MT1-MMP. It is likely that this mechanism is also involved in the phagocytic degradation of GDSC disks by macrophages. In this respect it is of interest that macrophages in the HDSC disks only show expression of MT1-MMP but not of Endo180, the latter being the reason why phagocytosis is not observed in HDSC.

A limitation of our study is, that we have not provided direct evidence that the Endo $180^{+} \mathrm{MT} 1-\mathrm{MMP}^{+} \mathrm{F} 4 / 80^{+}$cells indeed phagocytosed collagen, as we have not shown ingested collagen in the cells themselves by means of electron microscopy, or carried out any functional or knock-down studies. In addition, we cannot exclude the possibility that in addition to Endo180 other receptors are involved in the uptake of collagen, such as macrophage scavenger receptors (Greaves and Gordon, 2009). However, giant foreign body cells (that are formed as a result of macrophage fusion) do show pieces of collagen biomaterials intracellularly (Khouw et al., 2000), and collagen has so far not been reported as a ligand for scavenger receptors. It is therefore likely, that the reported correlations in this study are indicative of a mechanistic relationship between macrophage activation by IFN- $\gamma$ and collagen degradation and that involved mechanisms are comparable to those of fibroblast-mediated collagen degradation under physiological conditions.

Mechanisms on how the expression of Endo180 is regulated are not known. Another main finding of this study is that the pro-inflammatory cytokine IFN- $\gamma$ stimulates the expression of Endo180 in murine macrophages (RAW 264.7 cells), providing an explanation why phagocytosis 
A.

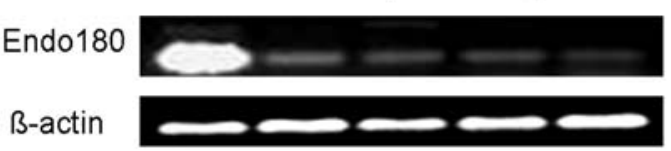

IFN- $\gamma(\mathrm{ng} / \mathrm{ml}) \quad 2.5 \quad 2.5 \quad 2.5 \quad 2.5 \quad 2.5$

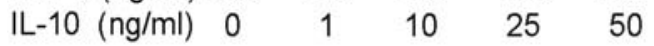

With collagen coating

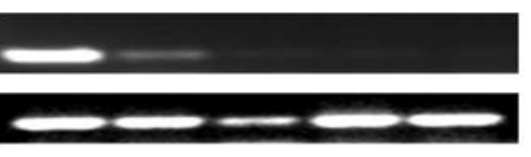

$\begin{array}{lllll}2.5 & 2.5 & 2.5 & 2.5 & 2.5\end{array}$

$\begin{array}{lllll}0 & 1 & 10 & 25 & 50\end{array}$

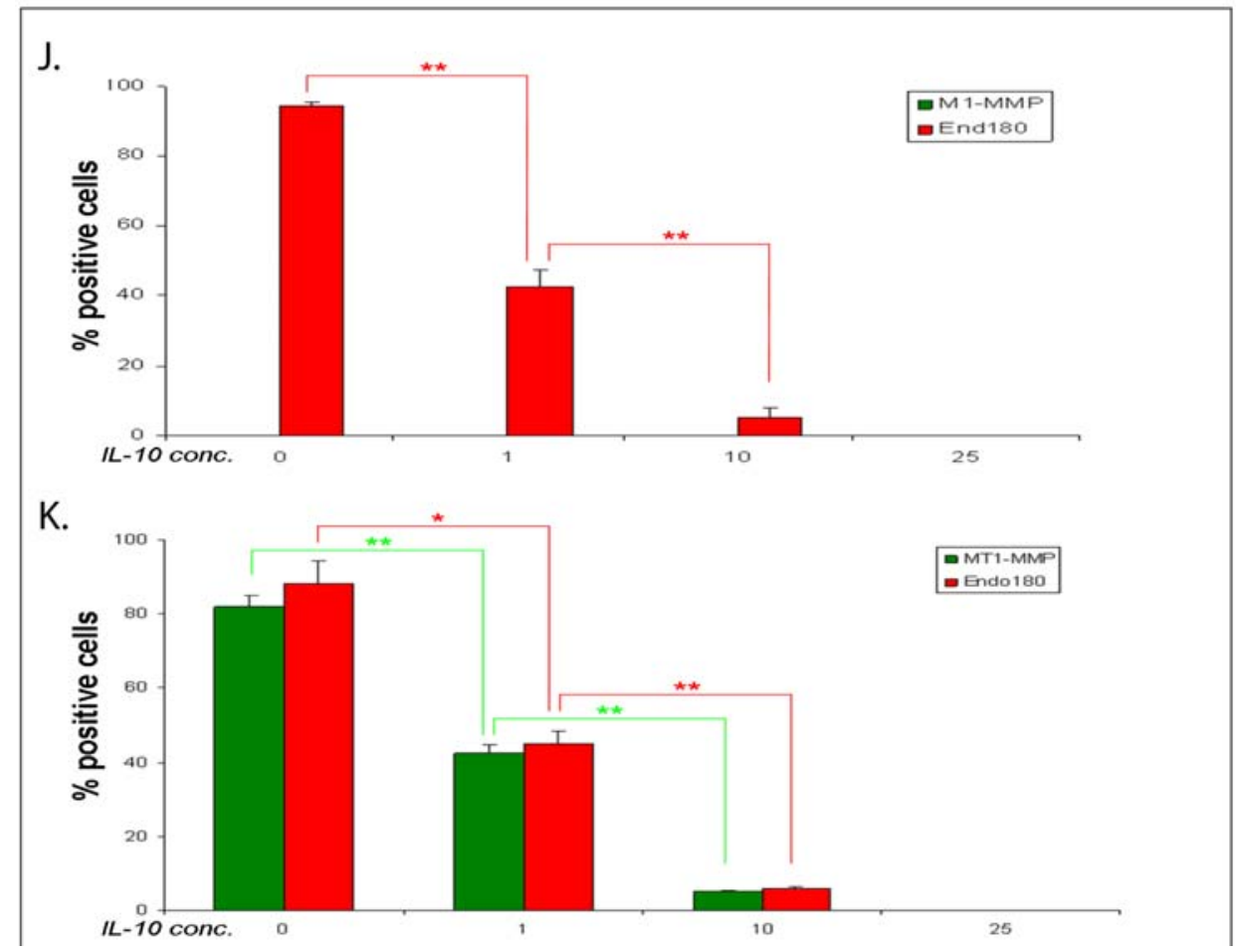

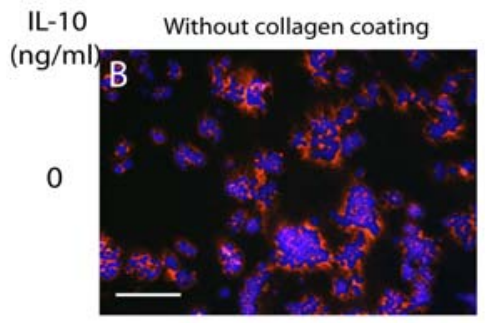
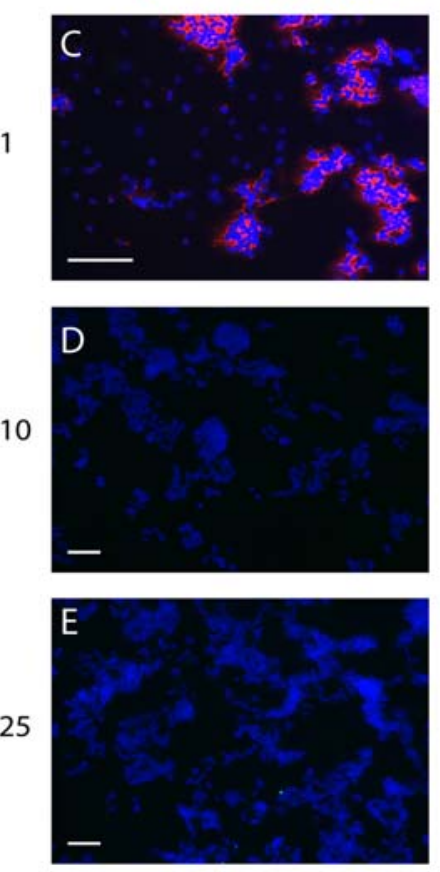
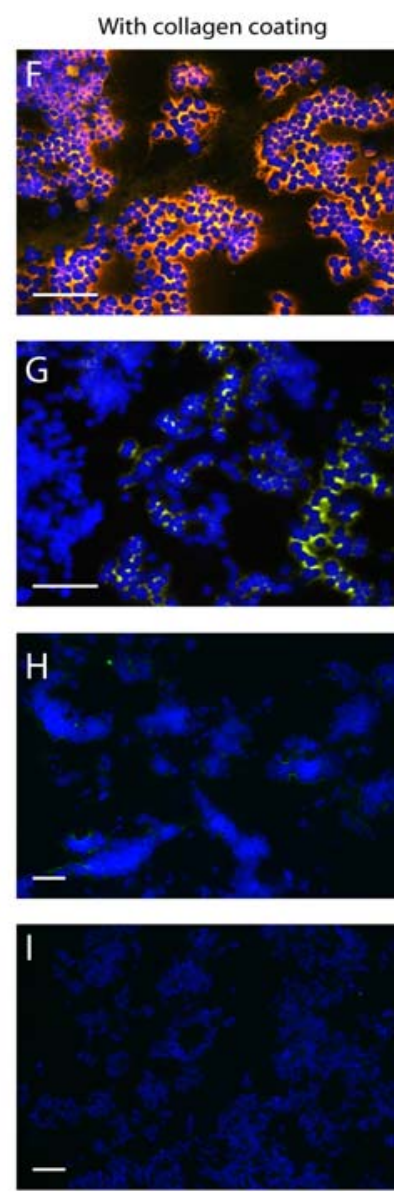

Fig. 6. IL-10 inhibits the expression of Endo 180 and/or MT1-MMP induced by IFN- $\gamma$ in RAW 264.7 cultured with/without collagen coating as determined by gene transcript and protein expression analyses. Cells were treated with $0-1$ $10-25-50 \mathrm{ng} / \mathrm{ml}$ of IL-10, with the presence of $2.5 \mathrm{ng} / \mathrm{ml} \mathrm{IFN-} \gamma$, for $48 \mathrm{~h}$. Next, cells on 6-well cell culture plates and 6-well diagnostic slides were used for RTPCR and immunofluorescent staining, respectively. Regardless with collagen coating or not, the mRNA levels of Endo180 induced IFN- $\gamma$ was decreased rapidly at $1 \mathrm{ng} / \mathrm{ml}$ IL-10 and almost absent at $10 \mathrm{ng} / \mathrm{ml}$ or above (A). The protein expression was consistent with the gene expression: expression of IFN- $\gamma$ induced Endo 180 was $50 \%$ blocked by the exposure of the cells to $1 \mathrm{ng} / \mathrm{ml}$ IL-10, and was totally blocked at concentrations of $25 \mathrm{ng} / \mathrm{ml}$ IL-10, as shown in the merged picture of double staining of Endo 180 and MT1-MMP (B-I) and quantification of the positive cells without collagen coating (J) or with collagen coating $(\mathrm{K})$. Cell nuclei were stained with DAPI (blue). Values are depicted as mean \pm S.D. $(\mathrm{n}=5) .{ }^{*}=P<0.05 ; * *=P<0.01$. Scale bar $=50$ $\mu \mathrm{m}$. 
is seen only at day 2 and 21: only at these time points a high expression of IFN- $\gamma$ is seen in GDSC disks. Interestingly, IFN- $\gamma$ also induced the expression of MT1MMP in RAW 264.7 cells, but only when the cells were plated on a collagen coating. This shows the importance of choosing the correct substrate when studying the response of macrophages towards cytokines.

Interestingly, we have found in the current study that the anti-inflammatory cytokine IL-10 is able to counteract the expression of Endo180 as induced by IFN- $\gamma$. The microenvironment between the GDSC and HDSC disks differs with respect to IL-10 levels: a higher level of IL10 is seen in HDSC disks compared to GDSC disks (Ye et al., submitted). The presence of lower levels of IFN- $\gamma$ in HDSC disks in combination with higher levels of IL-10 provides an explanation why phagocytosis of collagen by macrophages did not occur within HDSC disks.

In summary, we conclude that MT1-MMP and Endo180 seem to be involved in the phagocytic processing of collagenous biomaterials by macrophages through the ability of macrophages to cleave collagen fibrils near the cell membrane by MT1-MMP followed by the lysosomal delivery of cleaved collagen aggregates via binding to Endo180. In addition, the expression of Endo180 and MT1-MMP is induced by IFN- $\gamma$ in the presence of collagen. Based on these results, regulation of phagocytosis of collagen by macrophage may be feasible through modulation of the expression level of IFN- $\gamma$, or through the addition of anti-inflammatory factors that counteract with IFN- $\gamma$, e.g. IL-10.

\section{Acknowledgements}

This study was supported by RuG Jan Kornelis de CockStiching (Q. Ye). The authors wish to acknowledge the excellent technical support of Mr. Jasper Koerts, Ms. Saskia de Rond and Mrs. Linda Brouwer.

\section{References}

Anderson JM, Jones JA (2007) Phenotypic dichotomies in the foreign body reaction. Biomaterials 28: 5114-5120.

Anderson JM, Rodriguez A, Chang DT (2008) Foreign body reaction to biomaterials. Semin Immunol 20: 86-100.

Austyn JM, Gordon S (1981) F4/80, a monoclonal antibody directed specifically against the mouse macrophage. Eur J Immunol 11: 805-815.

Badylak SF, Valentin JE, Ravindra AK, McCabe GP, Stewart-Akers AM (2008) Macrophage phenotype as a determinant of biologic scaffold remodeling. Tissue Eng A 14: 1835-1842.

Beertsen W, Holmbeck K, Niehof A, Bianco P, Chrysovergis K, Birkedal-Hansen H, Everts V (2002) On the role of MT-1-MMP, a matrix metalloproteinase essential to collagen remodeling, in murine molar eruption and root growth. Eur J Oral Sci 110: 445-451.

Behrendt N, Bugge TH (2003) uPARAP/Endo180 is essential for cellular uptake of collagen and promotes fibroblast collagen adhesion. J Cell Biol 160: 1009-1015.
Brown BN, Valentin JE, Stewart-Akers AM, McCabe GP, Badylak SF (2009) Macrophage phenotype and remodeling outcomes in response to biologic scaffolds with and without a cellular component. Biomaterials 30: 14821491.

Ciapetti G, Verri E, Granchi D, Cenni E, Gamberini S, Benetti D, Mian M, Pizzoferrato A (1996) In vitro assessment of phagocytosis of collagen by human monocytes/macrophages using a spectrophotometric method. Biomaterials 17: 1703-1707.

Curino AC, Engelholm LH, Yamada SS, Holmbeck K, Lund LR, Molinolo AA, Behrendt N, Nielsen BS, Bugge TH (2005) Intracellular collagen degradation mediated by UPARAP/Endo180 is a major pathway of extracellular matrix turnover during malignancy. J Cell Biol 169: 977985.

Deporter DA (1979) Collagen phagocytosis by stimulated mouse peritoneal macrophages in vitro. $\mathrm{J}$ Periodontal Res 14: 323-331.

Dinnes DL, Santerre JP, Labow RS (2008) Influence of biodegradable and non-biodegradable material surfaces on the differentiation of human monocyte-derived macrophages. Differentiation 76: 232-244.

East L, McCarthy A, Wienke D, Sturge J, Ashworth A, Isacke CM (2003) A targeted deletion in the endocytic receptor gene Endo180 results in a defect in collagen uptake. EMBO Rep 4: 710-716.

Engelholm LH, List K, Netzel-Arnett S, Cukierman E, Mitola DJ, Aaronson H, Kjoller L, Larsen JK, Yamada KM, Strickland DK, Holmbeck K, Dano K, BirkedalHansen H, Behrendt N, Bugge TH (2003a) uPARAP/ Endo180 is essential for cellular uptake of collagen and promotes fibroblast collagen adhesion. J Cell Biol 160: 1009-1015.

Everts V, van der Zee E, Creemers L, Beertsen W (1996) Phagocytosis and intracellular digestion of collagen, its role in turnover and remodeling. Histochem J 28: 229245.

Greaves DR, Gordon S (2009) The macrophage scavenger receptor at 30 years of age: current knowledge and future challenges. J Lipid Res 50: S282-S286.

Honardoust HA, Jiang G, Koivisto L, Wienke D, Isacke CM, Larjava H, Hakkinen L (2006) Expression of Endo180 is spatially and temporally regulated during wound healing. Histopathology 49: 634-648.

Inouye S, Iyama K, Usuku G (1983) A freeze-fracture study of two types of collagen-phagocytosing cell in the post-partum rat endometrium. Virchows Arch B Cell Pathol Incl Mol Pathol 42: 243-249.

Khouw IMSL, van Wachem PB, de Leij LFMH, van Luyn MJA (1998) Inhibition of the tissue reaction to a biodegradable biomaterial by monoclonal antibodies to IFN-gamma. J Biomed Mater Res 41: 202-210.

Khouw IMSL, van Wachem PB, Molema G, Plantinga JA, de Leij LFMH, van Luyn MJA (2000): The foreign body reaction to a biodegradable biomaterial differs between rats and mice. J Biomed Mater Res 52: 439-446.

Kjoller L, Engelholm LH, Hoyer-Hansen M, Dano K, Bugge TH, Behrendt N (2004) uPARAP/endo180 directs lysosomal delivery and degradation of collagen IV. Exp Cell Res 293: 106-116. 
Knapp W, Menzel J, Brunner H, Steffen C (1974) Phagocytosis of soluble collagen-anticollagen complexes and of particulate collagen by peritoneal macrophages. Z Immunitatsforsch Exp Klin Immunol 146: 283-291.

Lee H, Sodek KL, Hwang Q, Brown TJ, Ringuette M, Sodek J (2007) Phagocytosis of collagen by fibroblasts and invasive cancer cells is mediated by MT1-MMP. Biochem Soc Trans 35: 704-706.

Lee H, Overall CM, McCulloch CA, Sodek J (2006) A critical role for the membrane-type 1 matrix metalloproteinase in collagen phagocytosis. Mol Biol Cell 17: 4812-4826.

Lucattelli M, Cavarra E, de Santi MM, Tetley TD, Martorana PA, Lungarella G (2003) Collagen phogocytosis by lung alveolar macrophages in animal models of emphysema. Eur Respir J 22: 728-734.

Luttikhuizen DT, Harmsen MC, van Luyn MJA (2006a) Cellular and molecular dynamics in the foreign body reaction. Tissue Eng 12: 1955-1970.

Luttikhuizen DT, van Amerongen MJ, de Feijter PC, Petersen AH, Harmsen MC, van Luyn MJA (2006b) The correlation between difference in foreign body reaction between implant locations and cytokine and MMP expression. Biomaterials 27: 5763-5770.

Luttikhuizen DT, Dankers PY, Harmsen MC, van Luyn MJA (2007) Material dependent differences in inflammatory gene expression by giant cells during the foreign body reaction. J Biomed Mater Res A 83A: 879886.

Madsen DH, Engelholm LH, Ingvarsen S, Hillig T, Wagenaar-Miller RA, Kjoller L, Gardsvoll H, HoyerHansen G, Holmbeck K, Bugge TH, Behrendt N (2007) Extracellular collagenases and the endocytic receptor, urokinase plasminogen activator receptor-associated protein/Endo180, cooperate in fibroblast-mediated collagen degradation. J Biol Chem 282: 27037-27045.

Mosser DM, Edwards JP (2008) Exploring the full spectrum of macrophage activation. Nature Rev Immunol 8: 958-969.

Mousavi SA, Sato M, Sporstol M, Smedsrod B, Berg T, Kojima N, Senoo H (2005) Uptake of denatured collagen into hepatic stellate cells: evidence for the involvement of urokinase plasminogen activator receptor-associated protein/Endo180. Biochem J 387: 39-46.

Munirah S, Kim SH, Ruszymah BH, Khang G (2008) The use of fibrin and poly(lactic-co-glycolic acid) hybrid scaffold for articular cartilage tissue engineering: an in vivo analysis. Eur Cell Mater 15: 41-52.

Olde Damink LH, Dijkstra PJ, van Luyn MJA, van Wachem PB, Nieuwenhuis P, Feijen J (1995) Changes in the mechanical properties of dermal sheep collagen during in vitro degradation. J Biomed Mater Res 29: 139-147.

Parakkal PF (1969) Involvement of macrophages in collagen resorption. J Cell Biol 41: 345-354.

Sachlos E, Gotora D, Czernuszka JT (2006) Collagen scaffolds reinforced with biomimetic composite nano-sized carbonate-substituted hydroxyapatite crystals and shaped by rapid prototyping to contain internal microchannels. Tissue Eng 12: 2479-2487.
Sheikh H, Yarwood H, Ashworth A, Isacke CM (2000) Endo180, an endocytic recycling glycoprotein related to the macrophage mannose receptor is expressed on fibroblasts, endothelial cells and macrophages and functions as a lectin receptor. J Cell Sci 113: 1021-1032.

Svoboda ELA, Deporter DA (1980) Phagocytosis of exogenous collagen by cultured murine fibroblasts and macrophages: A quantitative electron microscopic comparison. J Ultrastruct Res 72: 169-173.

Tai H, Mather ML, Howard D, Wang W, White LJ, Crowe JA, Morgan SP, Chandra A, Williams DJ, Howdle SM, Shakesheff KM (2007) Control of pore size and structure of tissue engineering scaffolds produced by supercritical fluid processing. Eur Cell Mater 14: 64-77.

Thomas EK, Nakamura M, Wienke D, Isacke CM, Pozzi A, Liang P (2005) Endo180 binds to the C-terminal region of type I collagen. J Biol Chem 280: 22596-22605.

Valentin JE, Stewart-Akers AM, Gilbert TW, Badylak SF (2009) Macrophage participation in the degradation and remodeling of extracellular matrix scaffolds. Tissue Eng Part A 15: 1687-1694.

Van Putten SM, Wubben M, Hennink WE, van Luyn MJA, Harmsen MC (2009) The downmodulation of the foreign body reaction by cytomegalovirus encoded interleukin-10. Biomaterials 30: 730-735.

Van Wachem PB, van Luyn MJA, Olde Damink LH, Dijkstra PJ, Feijen J, Nieuwenhuis P (1994) Biocompatibility and tissue regenerating capacity of crosslinked dermal sheep collagen. J Biomed Mater Res 28: 353-363.

Wienke D, MacFadyen JR, Isacke CM (2003) Identification and characterization of the endocytic transmembrane glycoprotein Endo 180 as a novel collagen receptor. Mol Biol Cell 14: 3592-3604.

Yeghiazaryan K, Skowasch D, Bauriedel G, Schild H, Golubnitschaja O (2007) Could activated tissue remodeling be considered as early marker for progressive valve degeneration? Comparative analysis of checkpoint and ECM remodeling gene expression in native degenerating aortic valves and after bioprosthetic replacement. Amino Acids 32: 109-114.

\section{Discussion with Reviewer}

Reviewer I: A crucial point is the question whether macrophages do indeed phagocytose fibrillar collagen. There are, as far as I am aware, no data available that demonstrate such a capacity by these cells. In the study of Lucattelli et al. (2003) (text reference) the macrophages have ingested a very peculiar form of collagen. These crystalloid structures were shown to contain collagen but this collagen is quite different from fibrillar collagen. Please comment.

Authors: Although it is intuitive and logical that phagocytic cells such as macrophages would play an important role in the clearance of collagen scaffolds by 
means of phagocytosis, we have to admit, after consulting the literature, that there is indeed remarkable little data to support this. After an extensive search, we found only a few (old) papers that show without reasonable doubt the presence of intracellular aggregated collagen material in macrophages (Parakkal, 1969; Knapp et al., 1974; Deporter, 1979; Svoboda and Deporter, 1980; Inouye et al., 1983; Ciapetti et al., 1996; text references). Luccatelli et al. (2003) showed that the crystalloid structures are of a collagenous nature. They do differ from fibrillar collagen, but in the context of our study this is of less relevance: collagen scaffolds are treated extensively, and part of the collagen in the scaffold does not show its normal structure anymore (such as the typically banded structure). 